\title{
Current and Voltage Harmonic Analysis of the Oil Production Enterprise with Abruptly Variable Load
}

\author{
Vyacheslav Zyryanov ${ }^{1}$, Roman Khatylenko ${ }^{1 *}$, and Anton Potapenko ${ }^{2}$ \\ ${ }^{1}$ Novosibirsk State Technical University, Karl Marx pr. 20, Novosibirsk, Russia \\ ${ }^{2}$ LLC «Energy Storage Systems», Serebrynnikovskaya str.14/1, Novosibirsk, Russia
}

\begin{abstract}
The monitoring results of $6 \mathrm{kV}$ diesel power plant mode parameters are presented in the paper. The diesel power plant supplies the drilling unit of the oil production enterprise. The main goal of the paper is to estimate electric power quality indexes connected with voltage unsinusoidality of the monitored offgrid power system, to compare them with specified in State Standard 32144-2013 [1] and to provide high harmonics reduce methods. The real mode parameters measurements of $3600 \mathrm{kVA}$ diesel power plant in different technological processes connected with oil production were used during the research. The MATLAB software and integrated Fourier transform function were applied to elaborate the mode parameters measurements. Based on harmonic analysis generalized results it is obtained that in many technological processes electric power quality indexes fail to meet the requirements of State Standard 32144-2013 [1]. The filter compensating device with reactive power 1350 kvar installed on $6 \mathrm{kV}$ bus doesn't allow to supply required electric power quality indexes. The DC drive thyristors rectifiers and the frequency converters of the asynchronous motors of the drill unit parts are the main sources of high harmonics in steady-state modes. The harmonic composition essential changes and electric power quality indexes are reduced due to load power dumps and surges. The high harmonics in such modes are caused by transients in synchronous generators providing supply of the considered power system. The quick-operating electric energy storage system with active power filter function [2] has been proposed as a method to reduce the harmonics.
\end{abstract}

\section{Introduction}

Since last decades the number of rectifier load with nonlinear current-voltage characteristics has increased [3]. It's generally caused by technological advance in power electronics and wide integration of different types of rectifiers, mostly power converters. With increased amount of power converters, the load nodes characteristics are described by variable-frequency electric drive, instead of asynchronous drive, like it was before.

These circumstances lead to electric power quality decreasing first of all, because of high harmonics generation.

This problem is essential in off-grid power systems of oil production enterprise, where harmonic level is connected with rectifier techniques, hard operating modes and specific character of technological processes.

Noncorresponding of power quality index values such as nth voltage harmonic component index $(\mathrm{KU}(\mathrm{n})$, $\%)$ and total voltage harmonic component index (KU, \%)with State Standard 32144-2013 [1] leads to serious economic and technical consequences, especially for electrical equipment with capacitive impedance, which become small on high frequencies. That is the reason of accelerating of cable insulation deterioration [4] and increasing of filter-compensating device harmonic current overload [5]. Besides, harmonics lead to high additional power losses in all power system elements, firstly, in electrical machines. Power quality issues are especially essential in off-grid supply power systems, where consumers' load is comparable with generators' power. Such situation is typical for most part of oil production enterprises, which load frequently has abruptly variable character.

That is why the measures of reducing harmonic level is required. Nowadays this issue is generally settled with passive L and LC filters, less often with active power filters. Currently energy storage systems with active power filter function, which allow to compensate abruptly variable active and reactive load changes and reduce harmonic level, become very prospective [5].

To obtain authentic information about electric power quality and current and voltage harmonic composition of oil production enterprise supply power system, the monitored mode parameters of diesel power plant has been conducted by LLC «Energy Storage Systems» employees.

\section{The description of load composition and technological processes}

romankhatylenko@mail.ru 
The process of borehole constructing is consisted of iterative operations: tool running, destruction a stone with drill bit and mud flush - drilling, drill-pipe connection and trip out hole for changing run-out drill bit. Discharge pumping of mud flush into borehole by the flush pump [6]. Besides that, in some cases the additional works such as reaming, well cleanout, geophysical analysis and tests are carried out. The main load is electric drives of drill unit different parts. The rotary drilling method is applied in monitored enterprise. The drill bit is not only scrabbles into rock, but also shear it off because of rotating moment [7].

The electrical equipment of the drill unit is connected to metal-clad switchgear by cable lines.

The filter compensating device is connected to $6 \mathrm{kV}$ bus and configured on 5th and 7th harmonics.

On $0.4 \mathrm{kV}$ side there are handling winch asynchronous motor with frequency converter; DC drive of the pumps, rotor, winch, bit feeds (DC motor and thyristor rectifier); household consumers and boiler house; drill unit control systems.

On $0.69 \mathrm{kV}$ side there are asynchronous motor of the top drive system with frequency converter; DC drive of the pumps, rotor, winch and thyristor rectifiers.

When tool running the winch DC drive is the most loaded. In this operating mode the energy consumption of drill unit is low and abrupt changes of the operating mode are insignificant. Therefore, current and voltage distortion is low.

When drilling the winch and rotor DC drives are the most loaded. The rotor is especial mechanism that rotate drill-pipe and drill bit connected to it. Also the DC drive of the pump is operating in this process [6].

The power consumed by drill unit is essentially increasing in drilling mode and engines operating conditions is getting worse [7], that leads to current and voltage distortion. It is especially notable when load power dumps and surges. The highest abruptly variable load changes could reach $1.5 \mathrm{MW}$ in monitored power system.

The drill-pipe connection process is characterized by drilling interruption and addition of extra pipes to make drill-pipe longer [6]. The distortion of mode parameters is low. After drill-pipe connection the drilling process is proceeding.

For changing run-out drill bit the trip out hole is conducted. In such mode winch DC drive is operating under heavy loads. That results to high unsinusoidality level of current and voltage.

The reaming of drilled section is applied to eliminate local resistance (ledges, bridges, deviations, etc.), which could lead to inability to run frill unit to the bottom [8]. The reaming is repeated running of the borehole. The load on the equipment in this case is less than in drilling process.

The well cleanout is necessary for cleaning borehole lower level from sand and other mud. During well cleanout the flush water is delivered to the borehole through wash pipe [9]. In this case the most loaded drives are the winch DC drive and the flushing pipe DC drive.

The geophysical analyses of the borehole were conducted in monitored object. The works referred to conducting researches and measurements (geophysical, geological and others) in different technological process. The mode parameters in this case depend on the previous technological process mode parameters.

\section{Analysis of the current and voltage harmonic composition}

Choosing of harmonic reduce method and calculation of parameters is based on current and voltage harmonic analysis in different operating modes.

Harmonic current components and Total Harmonic Distortion - THD I (1) aren't specified in Russian Federation state standards. The estimation of distortion is conducted only for voltage signal with index $K_{U}$ (2). Nevertheless, it's important to understand which current harmonics appear in load current, because that harmonics are responsible for voltage drops on grid elements and voltage signal distortion, and that harmonics should be reduced. THD in generally is calculated according to State Standard 30804.4.7-2013 [10] and could be applied as for current, as for voltage:

$$
\text { THD }_{Y}=\sqrt{\sum_{h=2}^{h_{\max }}\left(\frac{Y_{H, h}}{Y_{H, 1}}\right)^{2}},
$$

for voltage that index is applied in next form:

$$
K_{U}=\sqrt{\sum_{h=2}^{40}\left(\frac{U_{h}}{U_{1}}\right)^{2}},
$$

where $Y$ - signal index (current $I$ or voltage $U$ ); $h$ harmonic number - multiple integer of the main supply frequency; $h_{\max }$ - maximal harmonic number (usually applied as 40); $Y_{H, h}-$ rms value of harmonic with number $h ; Y_{H, 1}-$ rms value of the first harmonic; $U_{h}-$ rms value of voltage harmonic with number $h ; U_{l}-\mathrm{rms}$ value of the first voltage harmonic.

Fig. 1 shows $6 \mathrm{kV}$ mode parameters oscillography records in drilling process from 3989.5 to $4013.9 \mathrm{~m}$. The harmonic analysis is conducted for framed area. In current and voltage signal spectrums the dominant harmonics are odd not multiple of three. The magnitudes of $11^{\text {th }}, 17^{\text {th }}$ and $23^{\text {th }}$ harmonics are the highest. Also there are interharmonics in signal spectrums. Fig. 2 demonstrates the results with interharmonics. 


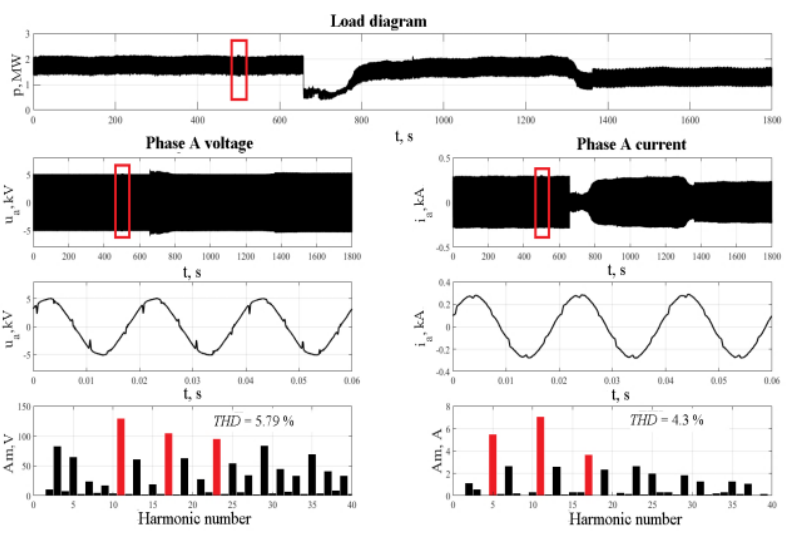

Fig. 1. Typical mode parameters oscillography record in steady-state drilling process.

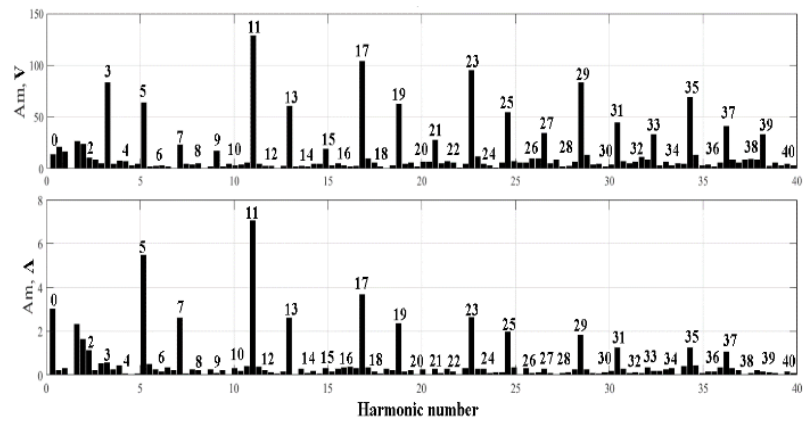

Fig. 2. The harmonic analysis results with interharmonics.

It should be especially noted that with abruptly variable mode change (load power dumps and surges), the voltage and current harmonic compositions become atypical. In such cases the dominant harmonic is the second. The example of load surge during trip out hole from 2676 to $43 \mathrm{~m}$ process is presented on fig. 3 and harmonic analysis is presented on fig. 4.

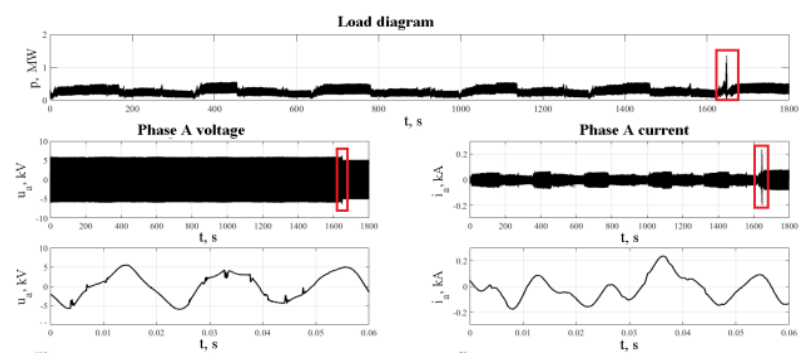

Fig. 3. The example oscillography record with load surge.

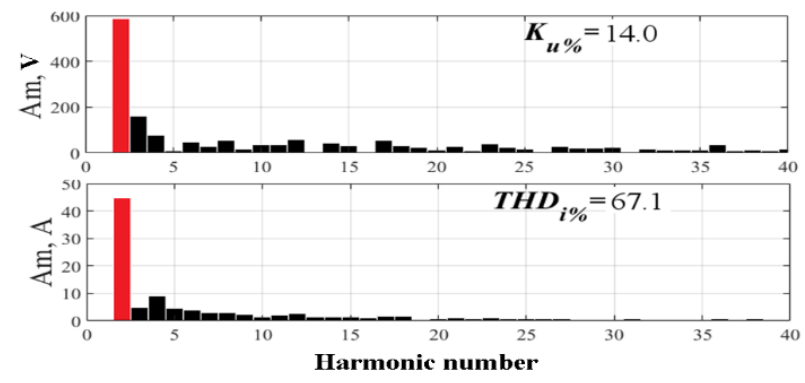

Fig. 4. The harmonic analysis results during load surge (without main frequency component).
With abruptly variable operating mode change of the generator, that is common for off-grid power plants with abruptly variable load, the aperiodic currents in stator windings appears. As magnetic flux of aperiodic current component changes slowly in time (in comparison with periodic component), it induces electromotive force in excitation winding with frequency, characterized by rotor speed. This electromotive force produces the same frequency current that produces magnetic flux, rotating with rotor. That pulsating magnetic flux could be presented as to equal magnitude fluxes (front $-\Phi_{\mathrm{F}}$ and reverse $-\Phi_{\mathrm{R}}$ ), rotating in opposite sides with rotor speed. It's obvious that one of them $\left(\Phi_{R}\right)$ is motionless relatively to stator, and another one $\left(\Phi_{\mathrm{F}}\right)$ is rotating with double frequency relatively to stator and induces the second current harmonic in stator windings $[11,12]$. Its magnitude is dominant in signal spectrum and atypical for normal steady-state operating modes of supply power system. Besides, it's not common measure to reduce even harmonics in such off-grid power systems.

The magnetic flux $\Phi_{\mathrm{R}}$, motionless relatively to stator, magnetize the generator's steel. Fig. 5 demonstrates the synchronous machine open-circuit characteristic. It presents the stator electromotive force dependence from excitation current. This characteristic allows to estimate the magnetic circuit saturation level [12]. From opencircuit characteristic and waveforms of fig. 3 and 4 it's clear that constant signed magnetic flux, magnetizing stator, could lead stator steel operating point to the saturation area on the nonlinear part of open-circuit characteristic. The generators parameters with abruptly variable load changes become nonlinear too, that results the additional current and voltage distortions and leads to additional power losses. Also the magnetic circuit saturation negatively impacts on transients quality because of increasing short-circuit current values, impacts to stability of the generator [13] and makes its controllability worse due to generator parameters wide range unpredictable variation.

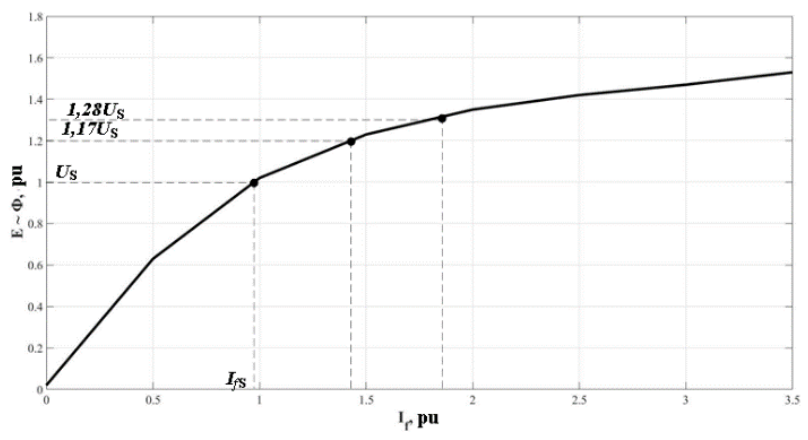

Fig. 5. Open-circuit characteristic.

Monitoring results analysis shows that with abruptly variable power load dumps and surges the voltage is 17$28 \%$ higher than rated supply voltage. From open-circuit characteristic it's seen that generator in this mode is operating on the nonlinear area of the characteristic because of stator saturation by pulsating magnet flux $\Phi_{\mathrm{R}}$. That magnet flux is induced by rotor periodic current component, which is induced by stator aperiodic 
component. The stator current aperiodic component appears in transients when power load dumps and surges appear. It's obtained that magnetic flux $\Phi_{\mathrm{R}}$ highly magnetizing stator steel will decrease $1.4-1.7 \mathrm{~s}$. It decreases with short circuit stator winding time constant $T_{a}[11]$, which ranges from 0.1 to $0.3 \mathrm{~s}$.

\section{Analysis results}

The harmonic analysis averaged results for the main technological processes and contribution of each process to the total monitoring time is presented in Table 1 . The odd harmonics $K_{U(n)}$ values, beginning with $11^{\text {th }}$ harmonic are higher than specified in State Standard 32144-2013 [1]. The $K_{U}$ values at almost all technological processes are higher than normal allowed $5 \%$. Despite of installed filter compensating device the $K_{U}$ values is higher than limit allowed $8 \%$ at drilling and trip out hole processes.

Table 2. Harmonic analysis results.

\begin{tabular}{|l|c|c|c|c|c|}
\hline Process & $\begin{array}{c}\text { Dominant } \\
\text { voltage } \\
\text { harmonics }\end{array}$ & $K_{U}, \%$ & $\begin{array}{c}\text { Dominant } \\
\text { current } \\
\text { harmonics }\end{array}$ & $\begin{array}{c}T H D_{I}, \\
\%\end{array}$ & $\begin{array}{c}\text { Process } \\
\text { contribution to } \\
\text { the total } \\
\text { monitoring time, } \\
\%\end{array}$ \\
\hline Drilling & $11,17,23$ & 8,26 & $5,11,17$ & 12,34 & 14,93 \\
\hline Reaming & $11,17,23$ & 6,27 & $5,11,17$ & 9,40 & 18,54 \\
\hline $\begin{array}{l}\text { Drill-pipe } \\
\text { connection }\end{array}$ & $7,11,17$ & 5,92 & $3,5,11$ & 13,52 & 4,65 \\
\hline Trip out hole & $11,17,23$ & 8,33 & $3,7,11$ & 13,85 & 30,42 \\
\hline Tool running & $3,11,17$ & 4,31 & $3,5,11$ & 10,17 & 12,85 \\
\hline Well cleanout & $11,17,23$ & 6,65 & $5,11,17$ & 13,71 & 8,40 \\
\hline $\begin{array}{l}\text { Geophysical } \\
\text { analysis }\end{array}$ & $11,17,23$ & 6,44 & $5,11,17$ & 7,72 & 6,25 \\
\hline
\end{tabular}

\section{Conclusion}

It is obtained that the harmonic composition is almost similar in all technological processes. The dominant voltage harmonics are $7^{\text {th }}, 11^{\text {th }}, 17^{\text {th }}$ and $23^{\text {th }}$. The dominant current harmonics are $5^{\text {th }}, 7^{\text {th }}, 11^{\text {th }}$ and $17^{\text {th }}$. The $11^{\text {th }}$ harmonic has the highest magnitude. Such harmonics are connected with 6-pulse DC drive rectifiers and frequency converters of the asynchronous motor, which generates $5^{\text {th }}, 7^{\text {th }}, 11^{\text {th }}, 13^{\text {th }}, 17^{\text {th }}, 19^{\text {th }}, 23^{\text {th }}, 25^{\text {th }}$ and other harmonics to the grid [14].

It should be especially noted that voltage and current harmonic compositions when load power dumps and surges becomes atypical for monitored power system and harmonics amplitudes become lot higher than in steady-state modes. It is most noticeable in drilling and trip out hole processes, when the saturation of the generator is possible.

The values of $T H D_{I}$ is increasing when the current magnitude is small and could reach more than $50 \%$. That is why there is no direct correlation between $K_{U}$ and $T H D_{I}$ (the magnitudes of current harmonics are not high enough to add distortion in the voltage waveform).

Monitoring results analysis demonstrates that filter compensating device installed in supply power systems doesn't allow required electric power quality, especially in abruptly variable load change modes.
In recent times power providers which supply oil production enterprises are interested in energy storage systems application on their objects. Mainly it refers to power plants with gas reciprocating units. The main function of energy storage systems is to smooth active power surges and to compensate reactive power. But furthermore energy storage systems could operate as an active filter [2]. Considering multifunctionality of energy storage systems it is reasonable to apply them to increase electric power quality and decline conventional filter compensating devices.

\section{References}

1. State Standard 32144-2013 Electric energy. Electromagnetic compatibility of technical equipment. Power quality limits in the public power supply systems (Stantinform, Moscow, 2014).

2. M.A. Dybko, S.V. Brovanov, Active power filter with battery energy storage based on inverters with fixing diodes, Prospective methods and tools of intellectual systems, 110-119 (2015).

3. H. Akagi., H. E. Watanabe, M. Aredes, Instantaneous Power Theory and Applications to Power Conditioning (IEE Press, New Jersey, 2007).

4. V. N. Tulskiy, I. I. Kartashev, High current harmonics impact on cable operating modes in $380 \mathrm{~V}$ distribution grid, Electric power quality, 5, 69-72 (2013).

5. D. V. Kovalenko, Static capacitor bank failure appear with high harmonics in power supply systems, Young Scientist, 19, 39-44 (2016).

6. A. Y. Dmitriev Basics of borehole drilling technology, (Tomskii Politekhnicheskii Universitet, Tomsk, 2008).

7. S. G. Blanter, I. I. Sud Electrical equipment of oil and gas production (Moscow, Nedra, 1980).

8. R. A. Atlasov, T. U. Tugi The methods of hole redressing before running the casing, Arctica XXI. Technical sciences, 3, 29-33 (2015).

9. E. I. Bukhalenko, Y. G. Abdullaev The technique and technology of well cleanout (Moscow, Nedra, 1982).

10. State Standard 30804.4.7-2013 Electromagnetic compatibility of technical equipment. General guide on harmonics and interharmonics measuring instruments and measurement, for power supply systems and equipment connected thereto (Stanrtinform, Moscow, 2013).

11. S. A. Ulyanov, Electromagnetic transients in electric power systems (Moscow, Energiia, 1970).

12. V. Y. Bespalov, N. F. Kotelenets, Electrical machines (Moscow, Academiya, 2013).

13. P. S. Zhdanov, Stability issues of electric power systems (Moscow, Energiia, 1979).

14. Y. S. Zhelezko, Reactive power compensation and electric power quality improvement (Moscow, Energoatomizdat, 1985). 